\title{
Formononetin in clovers as a feeding deterrent against clover root weevil
}

\author{
JR Crush $^{1}$, P J Gerard ${ }^{1}$ and S Rasmussen ${ }^{2}$ \\ ${ }^{1}$ AgResearch Ruakura, PB 3123, Hamilton, New Zealand \\ ${ }^{2}$ AgResearch Grasslands, PB 11008, Palmerston North, New Zealand
}

\begin{abstract}
The effect of leaf feeding by adult clover root weevils on the isoflavonoid content of red and white clovers was investigated in a glasshouse experiment. Lines of both clovers previously selected for variation in formononetin content were used. A higher percentage of white clover leaves than red clover leaves were damaged by the weevils, and the high formononetin red clover was least readily eaten. The formononetin content of the white clovers did not differ between the selections, was much lower than in the red clovers, and did not change in response to weevil feeding. In both red clover lines, formononetin and biochaninA levels rose in response to weevil feeding, suggesting that both compounds have antifeedant properties against clover root weevil. Because high foliar levels of oestrogenic compounds like formononetin threaten fertility of grazing sheep it is concluded that plant breeding programmes should increase the levels of formononetin and/or biochaninA in clover roots to mitigate the impact of weevil larval feeding on roots and nodules.
\end{abstract}

\section{Introduction}

The pasture pest clover root weevil (CRW, Sitona lepidus) is now established over all of the North Island of New Zealand. Damage to white clover (Trifolium repens) in pastures has been sporadic, and sometimes severe. Adult CRW feed on clover leaves and are prolific egg layers. The youngest larvae feed on clover nodules while older larvae eat clover roots and stolons. The damage to nodules and roots lowers the plant's tolerance of edaphic stresses and also allows ingress of fungal pathogens. Some clover plants die, while growth of others is severely checked.

Red clover ( $T$. pratense) is not readily eaten by CRW if they have a choice of red and white clover and the isoflavone formononetin has been suggested as the mechanism for CRW resistance in red clover (Gerard et al. 2005). In subterranean clover isoflavonoids with feeding deterrent activity contribute in the plant's resistance to redlegged earth mite (Wang et al. 1998). CRW adults do however show some habituation to a red clover diet after no-choice feeding on the species (Gerard and Crush 2003). Some modern red clover cultivars show considerable promise under CRW pressure in intensively grazed dairy (Cooper et al. 2003) and sheep/beef (Crush et al. 2005) pastures, and are recommended for inclusion in seed mixtures where CRW is present (Crush et al. 2005). CRW larval root feeding caused a pronounced elevation in the formononetin content of red clover seedlings in a slant board (Hardwick and Prestidge 1996) experiment (Gerard et al. 2005). This is of concern because elevated levels of oestrogenic isoflavonoids such as formononetin can cause infertility in sheep (Kelly et al. 1979, 1980). The objective of the work reported here was to investigate the effect of CRW adult feeding on the formononetin content of red and white clover. 


\section{Materials and methods}

Plant material

Two red clover and two white clover lines were used in the experiment. The red clover lines were selected out of cv. Grasslands Pawera for high formononetin (Margot Forde Germplasm Centre No. FT1185) or low formononetin (FT1184 = cv. Grasslands G27) concentration. The white clover lines were selected out of cv. Grasslands Sustain for higher (C23853) and lower (C23855) formononetin concentration.

\section{Experimental}

Plants were raised from seedlings in $15 \mathrm{~cm}$ pots of a fertile potting mix with individual trickle irrigation, and set out in a randomised block design, in a temperature controlled glasshouse. Mean day/night temperatures in the glasshouse were $16.3^{\circ} \mathrm{C}$ and $12.1^{\circ} \mathrm{C}$ over the treatment period, with daylength maintained at $12 \mathrm{~h}$ by supplementary lighting. Leaf samples were collected from 6 replicates of each clover type after 50 days when the plants had grown to cover most of the pot surface. The samples were freeze-dried prior to analysis for isoflavone content. Cylindrical cages of clear acrylic were immediately placed over the remaining 320 plants (80 plants of each clover line). Each cage was $300 \mathrm{~mm}$ high, and closed by a clear acrylic lid with plastic mesh ventilation ports. The cages fitted closely inside the pot wall and were pushed a small way into the potting mix.

Adult weevils were collected locally from ryegrass/white clover pasture using a suction apparatus (modified Homelite HB180V blower/vac.). Eleven weevils were put into half the cages. After 7 days, 10 replicates of each treatment were harvested. The weevils were removed, the number of leaf notches counted, and samples of laminae freeze-dried for isoflavone analyses. This process was repeated on Day 14 using another 10 replicates of each treatment, and all the remaining cages and weevils were removed. Further leaf samples were collected and analysed at Day 21 and Day 28. The chemical data were analysed by ANOVA using Minitab, and the leaf notch data by ANOVA in Genstat.

Analytical

Fifty mg of freeze-dried, ground leaf material were weighed into $2 \mathrm{ml}$ screw-cap tubes and extracted with $1 \mathrm{ml} 80 \% \mathrm{MeOH} / 0.1 \%$ HOAc (30 min, RT, shaking). Extracts were centrifuged (13,000 g, $15 \mathrm{~min})$, supernatants transferred into glass vials and analysed by HPLC using UV and Fluorescence detection (Column: Phenomenex Luna RP C18 5u, $150 \mathrm{~mm} \times 4.6 \mathrm{~mm}$; Flowrate: $1 \mathrm{ml} / \mathrm{min}$ ); Detector A: Fluorescence (Exc. 250, Em. 418, Response time 1.5, Range $\times 1.6$, Sensitivity Low); Detector B: UV-PDA (PhotoDiodeArray), UV-maxplot; Solvent A: 99.9\% $\mathrm{H}_{2} \mathrm{O}, 0.1 \%$ Formic acid; Solvent B: 99.9\% Acetonitrile, 0.1\% Formic acid; Gradient: 0 min B 5\%, 6 min B 5\%, 11 min B 10\%, 26 min B 17\%, 31 min B 23\%, 41 min B 30\%, 45min B 50\%, 52min B 50\%, 55 min B 97\%, 59 min B 5\%, 70 min B 5\%. Compounds were quantified based on calibrations with known standards. The red clover lines were analysed for free formononetin and biochaninA and the conjugates of these isoflavonoids (glucosides, glucosylmalonates). The white clover lines were analysed for free formononetin and its conjugates, no biochaninA was detected in them.

\section{Results}

There were significant $(P<0.001)$ differences between the clover lines in the percentage of notched leaves at Day 7, and at Day $14(P<0.05)$ (Table 1$)$. There was 
less notching of the red clover than the white clover lines and the high formononetin red clover had the least notching on both dates.

Formononetin and biochaninA were the only compounds to show significant responses to CRW feeding, and then only in the red clovers. Total Formononetin levels were significantly elevated in leaves of the low formononetin $(P<0.05)$ and high formononetin $(P<0.001)$ red clovers in the plus weevil treatments. Total BiochaninA levels were significantly $(P<0.001)$ elevated in the plus weevil treatments of both red clover selections, and did not vary much between the two selections.

In the red clovers, formononetin and biochaninA concentrations had increased in all treatments at Day 28 (Figs. 1, 2). Similar trends were apparent but less marked in the white clovers where formononetin levels were much lower than in the red clovers and did not differ between the two selections (Fig. 1).

\section{Discussion}

The leaf notch data confirm previous observations that red clover is less preferred as a food source than white clover by adult CRW, and that high formononetin red clover is eaten less readily than low formononetin red clover (Gerard et al. 2005). The white clover lines did not differ significantly from each other in formononetin content under the experimental conditions and levels were very low compared with red clover. Therefore it was not possible to determine if adult CRW showed preferences between plants containing formononetin levels under $0.5 \mu \mathrm{g} / \mathrm{mg} \mathrm{DM}$.

Formononetin contents increased significantly in both the red clovers in response to CRW adult feeding. Similar increases in formononetin content have been recorded in red clover seedling roots damaged by CRW larval feeding (Gerard et al. 2005) and in foliage of the white clover cultivar Grasslands Huia following infection by leaf fungal pathogens (Wong and Latch 1971). Formononetin has already been shown to contribute to pest resistance in other Trifolium-pest combinations (Cook et al., 1995, Wang et al. 1998). This suggests that broadly-based pest resistance might be achieved through manipulation of the formononetin content of forage legumes.

Concentrations of formononetin and biochaninA generally increased in all treatments and plants over the 28 day experiment. Isoflavone levels increase in annual legumes as plants develop, but no information about developmental changes in isoflavones in perennial species has been located. However, the magnitude of the increases suggests that they were unlikely to be plant developmental effects. If the changes were related to some environmental factor associated with the acrylic cages they were not reversed when the cages were removed at the midpoint of the experiment.

No literature has been located on the effects of biochaninA on CRW.

BiochaninA acted as an antifeedant compound towards red legged earth mite in a membrane sachet bioassay (Ridsdill-Smith et al. 1995), and reduced fecundity and feeding of subterranean termites (Boue and Raina 2003). The elevation of biochainA levels we observed in response to CRW adult feeding suggests that this compound has a defence role in red clovers.

Clovers with high levels of formononetin in the leaves can cause infertility in sheep (Kelly et al. 1979, 1980). BiochaninA is mildly oestrogenic in laboratory assays but nothing is known about the dietary levels that would be necessary to reduce fertility in sheep. BiochaninA and formononetin levels did not appear to be correlated in the two red clovers, so breeding for different ratios of these compounds should be possible. Breeding clovers that produce high formononetin levels in foliage in response to insect 
predation will pose a risk to stock. Even if farmers are aware of the possibility of elevated formononetin in clover under pest attack, almost no farmers or advisors monitor levels of root herbivores in pastures. However, breeding for high levels of formononetin and BiochaninA in roots, or a rapid elevation of levels of these compounds in response to root herbivory seems like a good option. Forage legumes are well adapted to defoliation, so adult CRW feeding is tolerable. Our field observations are that damage to nodules and roots by CRW larvae is the most likely cause of plant ill-thrift and death when this pest species is abundant. Breeding clovers with high formononetin in roots is within current research capability and could improve clover vigour and persistence while safe-guarding stock from the negative impact of high leaf formononetin levels. Further research is needed to determine whether breeding for high levels of formononetin, biochaninA or some combination of these compounds in roots would give broad spectrum protection against the complex of other clover root herbivores and root diseases that infest New Zealand pastures.

Table 1 Percentage of red and white clover leaves notched by CRW adults after 7 and 14 days caged on the plants. The clovers were selection for high or low formononetin concentration.

\begin{tabular}{llll}
\hline Clover species & $\begin{array}{l}\text { Formononetin } \\
\text { conc. }\end{array}$ & Day 7 & Day 14 \\
Red & High & 84.3 & 75.5 \\
Red & Low & 88.8 & 79.4 \\
White & High & 97.6 & 87.0 \\
White & Low & 97.2 & 96.2 \\
s.e.d. & & 3.6 & 7.7 \\
\hline
\end{tabular}


Fig. 1. Formononetin concentrations ( $\mu \mathrm{g} / \mathrm{mg}$ leaf $\mathrm{DW}$ ) in red and white clover lines previously selected for low (A, C), or high (B, D) formononetin content, and either exposed (-) or not exposed (---- ) to clover root weevil adult feeding.
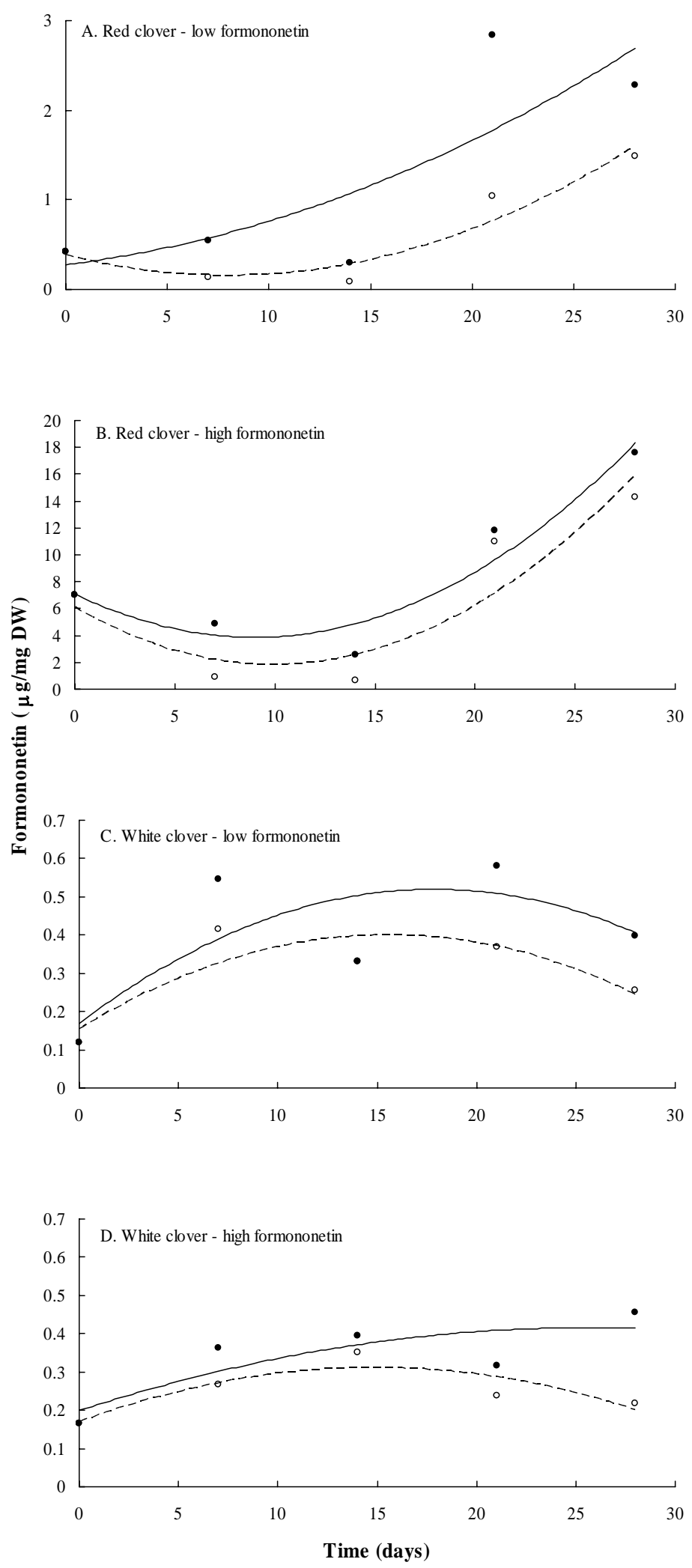
Fig. 2. BiochaninA concentrations ( $\mu \mathrm{g} / \mathrm{mg}$ leaf $\mathrm{DW}$ ) in red clover lines previously selected for low (A), or high (B), formononetin content, and either exposed (- ) or not exposed (---- ) to clover root weevil adult feeding.

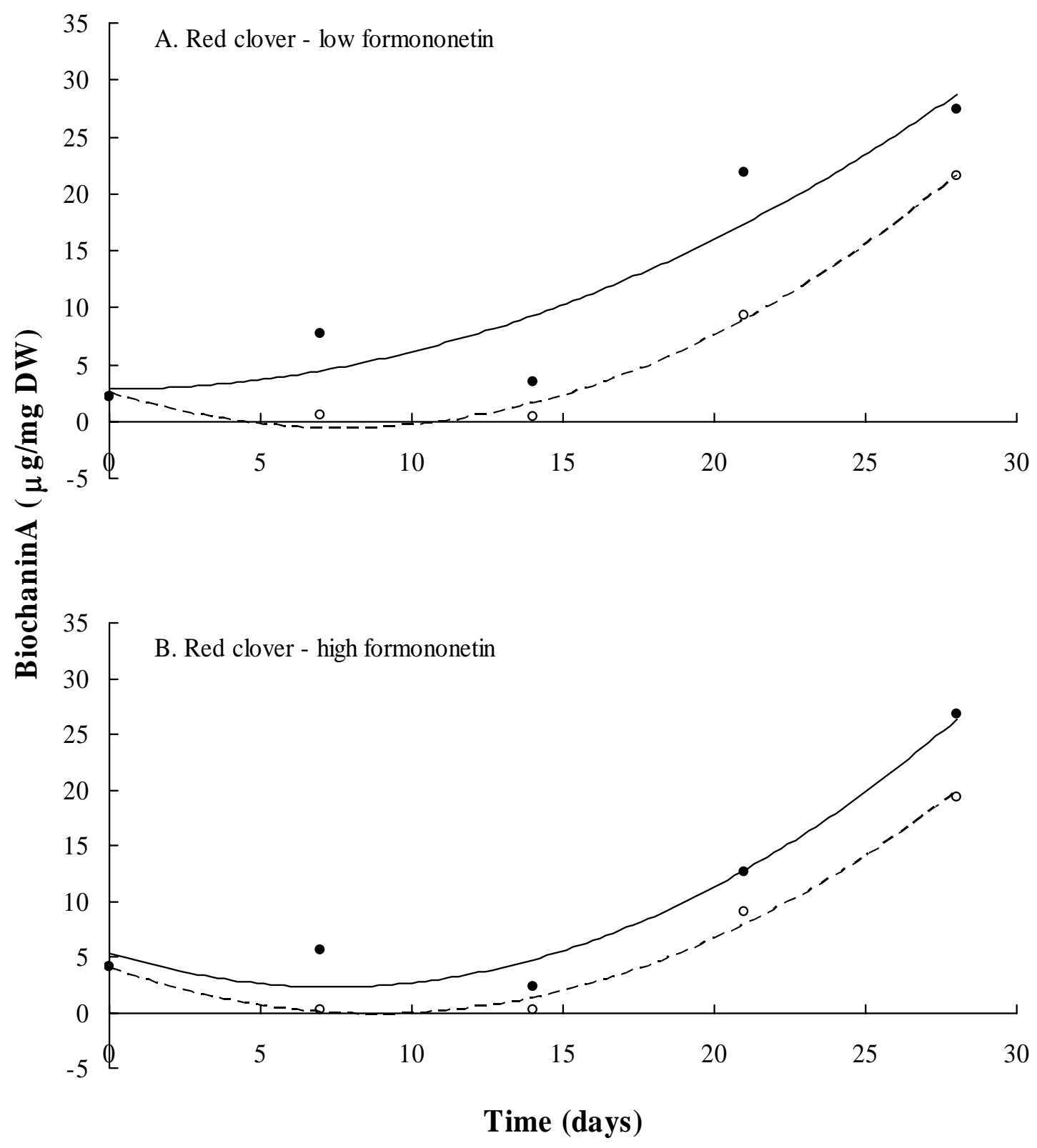




\section{Acknowledgements}

This work was supported by the Alma Baker Trust; Shirley Nichols, Tina Eden, Deborah Hackell, and Hong Xue for technical support. Dr Derek Woodfield and Dr Bill Rumball for supplying the clover seed.

\section{References}

Boue SE, Raina AK (2003) Effects of plant flavonoids on fecundity, survival, and feeding of the Formosan subterranean termite. Journal of Chemical Ecology (United States) 29, 2575-2584.

Cook R, Tiller SA, Mizen KA, Edwards R (1995) Isoflavonoid metabolism in resistant and susceptible cultivars of white clover infected with the stem nematode Ditylenchus dipsaci. Journal of Plant Physiology 146, 348-354.

Cooper BM, Crush JR, Woodfield DR, Willoughby B, Panckhurst KA (2003) Red clover - a legume showing tolerance to clover root weevil. Proceedings of the New Zealand Grassland Association 65, 153-156.

Crush JR, Cooper BM, Woodfield DR, Eerens JPJ, Gerard PJ, Watson RN, Davis LT (2004) Selection of pasture legumes for tolerance of clover root weevil. Proceedings of the $8^{\text {th }}$ Australasian Conference on Grassland Invertebrate Ecology 58-64.

Crush JR, Cooper BM, Woodfield DR, Gerard PJ (2005) Development of clover root weevil tolerant clovers. Proceedings of the New Zealand Grassland Association 76, 23-27.

Gerard PJ, Crush JR (2003) Feeding habituation to red clover by clover root weevil adults. New Zealand Plant Protection 56, 129-132.

Gerard PJ, Crush JR, Hackell DL (2005) Interaction between Sitona lepidus and red clover lines selected for formononetin content. Annals of Applied Biology 147, 173-181.

Hardwick S, Prestidge RA (1996) Effects of whitefringed weevil larval feeding on ryegrass and white clover in the laboratory. Proceedings of the 49th New Zealand Plant Protection Conference, 244-248.

Kelly RW, Hay RJM, Shackell GH (1979) Formononetin content of "Grasslands Pawera" red clover and its oestrogenic activity to sheep. New Zealand Journal of Experimental Agriculture 7, 31-134.

Kelly RW, Shackell GH, Allison AJ (1980) Reproductive performance of ewes grazing red clover (Grasslands Pawera) or white clover- grass pasture at mating. New Zealand Journal of Experimental Agriculture 8, 87-91.

Ridsdill-Smith TJ, Jiang Y, Ghisalberti EL (1995) A method of test compounds for feeding deterrence towards redlegged earth mite (Ascarine:Penthaleidae). Annals of Applied Biology 127, 593-600.

Wang SF, Ridsdill-Smith J, Ghisalberti EL (1998) Role of isoflavonoids in resistance of subterranean clover trifoliates to the redlegged earth mite Halotydeus destructor. Journal of Chemical Ecology 24, 2089-2100.

Wong E, Latch GCM (1971) Effect of fungal diseases on phenolic contents of white clover. New Zealand Journal of Agricultural Research 14, 633-638. 